\title{
Los orígenes del control informativo en las coberturas de guerra
}

\author{
Eva LAVÍn DE LAS HERAS \\ Universidad Camilo José Cela \\ elavin@ucjc.edu \\ Max RÖMER PIERETTI \\ Universidad Camilo José Cela \\ mwalter@ucjc.edu
}

Recibido: 2 de enero de 2015

Aceptado: 5 de mayo de 2015

\begin{abstract}
Resumen
La cobertura de los conflictos, desde sus inicios, ha estado muy ligada a la relación que han mantenido los militares y los medios. Desde la libertad de la que gozaban en sus primeros conflictos, aunque no exentos de problemas, pasando por la censura estricta que sufrieron en la Primera Guerra Mundial hasta el encorsetamiento al que se han tenido que enfrentar en las últimas guerras. La guerra de Vietnam marcaría un punto de inflexión en estas relaciones, y tras la invasión de Granada los militares pondrían en marcha un nuevo escenario informativo, el llamado "pool" informativo o agrupación de corresponsales. La falta de una guía clara y la lucha de ambos por controlar su espacio, ha hecho que las relaciones entre medios y militares sean siempre complicadas, por lo que las normas han ido evolucionando a cada conflicto marcando el futuro de las coberturas de prensa y por ende, el periodismo de guerra.
\end{abstract}

Palabras clave: pool informativo; corresponsales de guerra; medios de comunicación; Comisión Sidle.

\section{The origins of the control of information in war coverage}

\begin{abstract}
The conflict's coverage, since its inception, has been closely linked to the relationship that both the military and the media have. The freedom they maintained during their first conflicts, although not without problems, though they suffered strict censorship suffered during World War I, and lastly the straitjacket treatment that they have endured during recent wars. The Vietnam War marked a turning point in this relationship, and after the invasion of Grenada, the military would launch new information guidelines, called Department of Defense National Media Pool. The lack of clear guidance of both control and space, has made for a complicated relationship between media and military, so the rules have evolved after every conflict shaping the future of press coverage and thus, war reporting.
\end{abstract}

Key words: media pool; war correspondents; media; Sidle panel.

\section{Referencia normalizada}

Lavin de las Heras, E., Römer Pieretti, M. (2015). Los orígenes del control informativo en las coberturas de guerra. Historia y Comunicación Social. Vol 20, número 1, páginas 121-135. 
Sumario: 1. Introducción. 2. Invasión de Granada (1983). 3. Invasión de Panamá (1989). 4. Operación Escudo del Desierto y guerra del Golfo (1990-1991). 5. Conclusiones. 6. Referencias bibliográficas

\section{Introducción}

La relación entre los corresponsales de guerra y los militares ha sido complicada desde sus inicios. William Howard Russell, considerado uno de los primeros corresponsales, fue enviado a Malta, por el periódico británico The Times, en febrero de 1854 para cubrir la Guerra de Crimea. El 30 de marzo los militares británicos, tras evaluar su trabajo esos días, le permitieron viajar al frente y se embarcó con ellos rumbo a Gallipoli. Esto le permitió comprobar de primera mano que la guerra no discurría favorable a los británicos tal y como informaban, además de evidenciar numerosas deficiencias. Russell empezó a mandar crónicas más críticas, algo que también hizo el corresponsal del periódico London Daily News, Edwin Lawrence Godkin, provocando que la Armada británica no reconociera la figura de los corresponsales, privándoles así de asistencia y alimentación, por lo que tuvieron que valerse de sus propios medios para poder seguir la contienda.

El Gobierno británico además de negar todas las informaciones aparecidas en la prensa, para contrarrestar esta mala imagen y lo impopular que se estaba convirtiendo el conflicto, envió al que sería el primer fotógrafo de guerra, Roger Fenton, para que con sus imágenes demostrara la realidad maquillada, ya que no se le permitía retratar militares británicos heridos o muertos. Consideraban que el comportamiento de Russell y de su periódico era una traición a la Corona y a partir de febrero de 1856 aplicaron la censura militar, no permitiendo informar sobre la valía del enemigo y posibilitando la expulsión de los corresponsales que no lo cumplieran. Pero estas medidas, fueron tomadas demasiado tarde, aunque marcaron un precedente en las futuras coberturas, alcanzando su punto culmen en la Primera Guerra Mundial.

Durante la Gran Guerra, el Gobierno británico aplicó una censura férrea que le permitía examinar los telegramas que entraban y salían del frente además de poder censurar directamente a los periódicos. La prensa no sólo lo aceptó sino colaboró a transmitir la propaganda, lo que provocaría que el público dejara de tener esa fe ciega en ellos. Los corresponsales británicos, vestidos con ropas militares, se acabaron identificando con ellos, evitando ser críticos y dejándose absorber por la maquinaria propagandística, algo de lo que tras el conflicto, se avergonzarían.

El trabajo de los corresponsales durante un conflicto se ha visto influido en gran parte por la relación que tuvieran con los militares, fundamentalmente porque de ellos dependían para poder llegar al frente, enviar sus crónicas o hasta alimentarse. Pero también la tecnología ha tenido que ver en esta relación, ya que la evolución de ésta ha permitido que estos sean cada vez más independientes. El telégrafo, la televisión o los satélites de comunicación han hecho que los militares ya no puedan controlar toda la información que circula, por ello, sus normas suelen ser a cada 
conflicto más restrictivas, produciéndose una ruptura total entre militares y medios tras la guerra de Vietnam.

La televisión provocó un cambio en la forma en la que el mundo percibía una guerra, lo que tuvo consecuencias no sólo estratégicas sino también políticas durante la guerra de Vietnam. Se intentó aplicar la censura como en anteriores conflictos pero el alto número de corresponsales hizo que fuera imposible controlarles y que muchos acudieran al frente por sus medios, negándose a aceptar las informaciones oficiales. Pero a pesar de los reportajes de denuncia, sería la ofensiva guerrillera de los comunistas en el Tet, el acontecimiento que provocaría un cambio en la opinión pública, que retiraría su apoyo a los militares y a la Administración. Los americanos pudieron ver a través de la televisión los cuerpos muertos de los soldados americanos, la agonía de los heridos y la desesperación de los oficiales. Los militares entendieron que la prensa había transformado una derrota del Vietcong en una victoria psicológica para el enemigo, por lo que culparon a los medios de la derrota y su relación cambiaría definitivamente en los sucesivos conflictos.

Los británicos, aprendieron la lección y cuando en 1982, los militares argentinos invadieron las islas Malvinas, decidieron que sólo unos pocos periodistas británicos, diecisiete, les acompañarían obligándoles antes a firmar una declaración en la que se comprometían a respetar las normas de la censura militar. El Gobierno británico tuvo el control total de la información, consiguiendo, incluso, ocultar hechos que le hubieran perjudicado. El éxito de la operación marcó un antes y un después en las relaciones entre los militares y los medios, ya que ningún corresponsal volvería a tener la libertad con la que trabajarían en Vietnam.

Consideramos, por tanto, como objetivo fundamental estudiar las estrategias de comunicación que los militares americanos desarrollaron posteriormente con la creación del sistema "pool", para poder así entender las coberturas periodísticas de los sucesivos conflictos hasta la actualidad, parte fundamental de la historia del periodismo de guerra. Para ello, revisaremos las directivas, informes y documentación militar americana además de los estudios realizados durante esa época convulsa.

\section{Invasión de Granada (1983)}

El control que habían tenido los ingleses sobre la prensa en la guerra de las Malvinas, impresionó a los militares americanos que decidieron que en el futuro ninguna guerra se libraría de la censura, control y manipulación (Knightley, 2000).

El capitán norteamericano Arthur A. Humphries escribió en mayo de 1983, en la revista de la Escuela Naval: "A pesar de la percepción de opciones en una sociedad democrática, la Guerra de las Malvinas nos muestra cómo asegurarnos de que ciertas políticas de gobierno no sean socavadas por las formas en que se reportea una guerra" (...) "un acceso controlado a los combates, invocar la censura y brindar apoyo con 
un sentido patriótico en casa y en el campo de batalla. Tanto Argentina como Gran Bretaña nos mostraron cómo hacer primar la sabiduría” (Shor, 1998:69).

Sobre esta base, el Ejército de los Estados Unidos, que seguía creyendo que no hubieran perdido la guerra de Vietnam de no haber sido por la cobertura de los medios, se encargó de establecer una nueva estrategia informativa cuando invadieron la isla caribeña de Granada, antigua colonia británica, en la llamada operación "Furia Urgente".

Entre el 22 y el 24 de octubre de 1983, la situación política de Granada, y la del resto de islas del archipiélago, degeneró hasta desembocar en un golpe protagonizado por un grupo marxista que asesinó a su presidente, Maurice Bishop, y a otras treinta y cuatro personas, incluidos sus ministros. Con la invasión de Granada en la madrugada el 25 de octubre, Reagan "pasó de las palabras a los hechos cumpliendo con los principios sobre los que anunció que instalaba la Administración norteamericana: firmeza con los soviéticos, firmeza con el despliegue de euromisiles y firmeza con los aliados" (Morera Hernández, 2012:548).

Los militares americanos realizaron la operación con total secretismo para evitar a la prensa. Muchos de los jefes militares en Granada, habían sido oficiales durante la guerra de Vietnam, por lo que no tuvieron en consideración a los medios cuando planificaron la invasión. El vicealmirante Joseph Metcalf, solicitó que no hubiera reporteros en los inicios de la acción para no poner en peligro la seguridad no sólo de los ciudadanos y militares americanos sino también de los propios corresponsales. Esta petición fue apoyada por el presidente del Gobierno, y cuando los 600 corresponsales llegaron a las islas Barbados, no se les permitió a ninguno acompañar a las tropas durante la invasión, algo que se mantuvo durante las primeras 48 horas (Kim \& Paul, 2004).

Un reportero del Washington Post alquiló un yate para llegar a la isla, pero al poco de desembarcar, fue arrestado por los militares norteamericanos y apartado de las operaciones. Otros periodistas denunciaron que aviones compatriotas dispararon contra sus embarcaciones para desviarlos, por lo que nadie pudo acceder a la isla hasta que los militares dieron acceso (Shor, 1998). Sólo dos días después de la invasión las únicas imágenes que existían eran las captadas por lo camarógrafos militares, mostrándole al público sólo lo que quería que vieran, así la Administración se aseguraba el apoyo popular (English, 2005).

Tras la presión de la prensa y del Congreso, el general Vessey, ordenó a Metcalf, acomodar a los reporteros para que pudieran informar. Vessey consideró que la exclusión de la prensa en la operación desde el principio había sido un error (Belknap, 2002). Por lo que al tercer día, se escoltó a un grupo de 15 reporteros para que accedieran a la isla, una vez que la tenían bajo su control. El número de corresponsales fue aumentando hasta que en el quinto día se decretó el acceso libre (Kim \& Paul, 2004). Cuando los militares finalmente permitieron a los medios informar sobre lo sucedido, la cobertura fue en general positiva, pero también resaltó la incapacidad del Ejército y la Marina para comunicarse efectivamente entre ellos (English, 2005). 
Según Knightley (2000) esta acción se conocería como la "invasión no cubierta" ya que los medios sólo contaban con la información facilitada por la administración en la que se les mentía y desinformaba.

La prensa no tardó en reaccionar y en enero de 1984 las diez principales agrupaciones de medios informativos norteamericanos solicitaron a la Administración Reagan, mediante un escrito, su derecho no sólo histórico sino también constitucional, para justificar la presencia de corresponsales en el campo de batalla, afirmando que era un pilar de la democracia americana y que los ciudadanos tenían el derecho a saber: "Nuestra sociedad se mantiene sana y libre fundamentalmente porque nuestro público tiene una fuente independiente de información a su Gobierno" (The New York Times, 1984).

El general Vessey, un mes después, nombró una comisión para estudiar las relaciones entre los militares y los medios de comunicación y así, determinar la mejor manera de acomodar a la prensa en las operaciones militares (Belknap, 2002). La pregunta que se planteó fue: “¿Cómo debemos dirigir las operaciones militares de manera que salvaguardemos la vida de nuestros militares y protejamos la seguridad de las operaciones mientras mantenemos al público americano informado a través de los medios?" (Venable, 2002).

Para ello, se le encargó al general retirado Winant Sidle, dirigir la comisión junto a las principales organizaciones periodísticas de Estados Unidos, además de representantes de las cuatro ramas de las Fuerzas Armadas, de la oficina del Secretario de Defensa y del jefe del Estado Mayor. La comisión estableció ocho recomendaciones que fueron firmadas por todos los participantes el 23 de agosto de 1984. Estas propuestas tratarían de establecer un sistema viable para garantizar el acceso de los medios al campo de batalla en las futuras operaciones militares (Comisión Sidle, 1984):

1. Que la planificación de las operaciones militares se realizara simultáneamente con la planificación de los medios.

2. Cuando durante la planificación de las operaciones militares se advierte que la agrupación de corresponsales o pool sea el único medio factible de acceso a la operación, la planificación debe prever el grupo más grande posible, y minimizar el tiempo entre el sistema pool y la cobertura abierta para todos los medios.

3. En relación con el pool, el jefe del Estado Mayor recomienda al Secretario de Defensa que estudie la posibilidad de utilizar un listado preestablecido de corresponsales acreditados, en constante actualización, en caso de una operación militar. O el establecimiento de una lista de agencias de noticias para su uso en las mismas circunstancias.

4. Que el acceso de los medios a las operaciones militares debe ser voluntaria y que los medios de comunicación deben cumplir con las directrices de seguridad y reglas establecidas por el militar. Estas reglas deben ser las menos posibles y tienen que establecerse durante el proceso de planificación de cada operación. Las violaciones supondrían la exclusión del corresponsal/es. 
5. La planificación de las operaciones militares deben incluir equipamiento suficiente y personal militar cualificado cuya función sea ayudar adecuadamente a los corresponsales en la cobertura de la operación.

6. Los planificadores deben seleccionar cuidadosamente los medios de comunicación con los corresponsales para asegurar así una mayor rapidez. Sin embargo, estas comunicaciones no deben interferir en el combate ni en las operaciones de apoyo. Si es factible, los planes deben incluir las instalaciones de comunicaciones dedicadas a los medios de comunicación.

7. Se debe incluir en la planificación el transporte para los medios de comunicación tanto dentro como fuera del teatro de las operaciones.

8. El Secretario adjunto de Defensa para asuntos públicos militares se reunirá con los medios de comunicación, para incluir reuniones individuales, de forma regular, en las que se discutirían los posibles problemas entre los militares y los corresponsales durante las operaciones militares y ejercicios.

El objetivo del pool era identificar un pequeño grupo de reporteros que se "activaría" para cubrir las operaciones de última hora o las operaciones planeadas en secreto. Esto permitiría acceso a la prensa mientras que se salvaguarda la seguridad de las acción (Kim \& Paul, 2004). Pero en la parte final de las conclusiones, casi todos los representantes de los medios reflejan su clara oposición a los pools en general pero estaban de acuerdo en cooperar si era la única forma de tener acceso en los inicios de las actuaciones.

El pool fue el legado más concreto y visible de la comisión, esto permitía las coberturas independientes en los primeros estados del conflicto antes de que el acceso fuera total y abierto para el resto de medios. Esta limitación en el número de reporteros era justificada por los militares por razones de seguridad, secretismo o la incapacidad para transportar a todos (Cecil \& Sullivan, 1989). La exclusión de la prensa en la invasión de Granada, hizo que tras diez años de lucha, se acabaran estableciendo unos límites razonables al acceso de los medios a las zonas de combate (Terry, 1997).

En 1985, siguiendo las propuestas de la comisión, el Secretario de Defensa, se estableció el National Media Pool del Departamento de Defensa (DoDNMP) que se inspiraba no sólo en la propuesta de la comisión sino también en la experiencia que los británicos habían tenido en las Malvinas y que consistía en la selección de un grupo de corresponsales que acompañaría a los militares en los primeros estados de un conflicto o acción (Contreras \& Sierra, 2004). Para ello, se establecieron dos tipos de pool: el pool nacional y el pool regional (para una localización dentro del país). Los medios eran los encargados de sufragar algunos costes y el reportero debía estar listo para viajar en el pool en el momento en el que se anunciaba una operación (Cecil \& Sullivan, 1989).

El pool nacional estaba formado por corresponsales que residieran en Washington, tuvieran nacionalidad norteamericana y pasaporte en vigor. Además se les exigía que llevaran un saco para dormir, ropa adecuada para cualquier climatología y dinero para las comidas y eventualidades. Los militares se encargarían de proveerles del 
transporte, alojamiento y ropa adicional si el tiempo lo requiriera. Las comunicaciones también correrían a cargo de estos. El tamaño del grupo y la hora de la citación dependerían de las condiciones de la operación y del espacio disponible. Y los corresponsales asignados por cada medio, rotarían cada 90 días para que todos los medios pudieran estar presentes (Cecil \& Sullivan, 1989).

La idea es que los reporteros de este pool luego compartieran sus informaciones con los excluidos, consiguiendo así conciliar, por parte de los militares, una doble exigencia: garantizar la seguridad de los periodistas y controlar la información, porque el Ejército sólo les mostraba y les llevaba dónde querían. Esta idea de compartir noticias bélicas ya la utilizaron algunos medios en la Guerra Franco Prusiana, pero allí surgía por iniciativa de los propios periódicos para rentabilizar al máximo la labor de los periodistas enviados al frente y repartir el coste telegráfico (Bordería Ortiz, Laguna Platero \& Martínez Gallego, 1998).

Se estableció que el pool estaría formado por:

- Agencias de noticias: AP (Associated Press) y UPI (United Press Internacional) serían las agencias que tendrían prioridad. Viajaría siempre un corresponsal de cada una de ellas junto a un fotógrafo que iría rotando. Si la situación no lo permitiera, estaría un periodista de una agencia y el fotógrafo de la otra.

- Televisión: dos personas formarían el equipo, un corresponsal y un técnico. Los medios sugirieron un equipo de cada una de las cadenas ABC, CBS, NBC y CNN (un periodista, un cámara y un técnico de sonido, ya que dos personas les parecían insuficiente). El corresponsal de radio se quedó pendiente de resolver.

- $\quad$ Revistas: viajaría un reportero y un fotógrafo.

- Periódicos: al menos un reportero. Los criterios de selección dependería de la tirada y tenía que estar especializado en asuntos internacionales y que cubrieran habitualmente la información del Pentágono, por lo que no serían considerados más de $8-10$ periódicos.

Este modelo se testeó por primera vez en abril de 1985, pero se realizaron otras pruebas más para ejercitar a sus miembros (como podemos ver en el cuadro 1) (Cecil \& Sullivan, 1989).

Cuadro 1: Las primeras acciones del DoD National Media Pool desde sus inicios.

(Elaboración propia)

\begin{tabular}{|c|l|}
\hline Fecha & \multicolumn{1}{c|}{ Operación } \\
\hline Abril 1985 & $\begin{array}{l}10 \text { miembros del pool viajan cinco días a Honduras para cubrir la "Operación } \\
\text { Universal Trek 85". Aunque la noticia se filtró antes de que abandonaran } \\
\text { Washington fue un éxito. }\end{array}$ \\
\hline $\begin{array}{c}\text { Septiembre } \\
1985\end{array}$ & $\begin{array}{l}12 \text { corresponsales cubren durante un día la "Operación Double Eagle 85", } \\
\text { un ejercicio de entrenamiento de la brigada de asalto aérea. Se mantiene en } \\
\text { secreto y se realiza de manera satisfactoria. }\end{array}$ \\
\hline
\end{tabular}




\begin{tabular}{|c|c|}
\hline $\begin{array}{c}\text { Diciembre } \\
1985\end{array}$ & $\begin{array}{l}12 \text { miembros viajan en la operación de dos días, "Kernal Usher } 86-1 \text { ", un } \\
\text { ejercicio en el sur de California. Se requiere un refuerzo en el transporte para } \\
\text { que todos los miembros del pool puedan cubrir las diferentes localizaciones. } \\
\text { Se evidencia que las entrevistas por radio no se pueden grabar dentro de los } \\
\text { barcos por las interferencias eléctricas. }\end{array}$ \\
\hline Agosto 1986 & $\begin{array}{l}12 \text { corresponsales viajan durante dos días para la "Operación Gallant Eagle } \\
86 \text { ", cerca de Twentynine Palms en California. Es el primer pool en el que se } \\
\text { incluyen mujeres (dos), tres crónicas se retransmiten al Pentágono en una hora } \\
\text { cada una. }\end{array}$ \\
\hline Febrero 1987 & $\begin{array}{l}12 \text { reporteros cubren durante dos días un salto aéreo en Honduras. Por } \\
\text { primera vez se usa el fax para enviar las crónicas. Las informaciones de los } 3 \\
\text { grupos se recibieron en el Pentágono en una hora y } 10 \text { minutos; } 22 \text { minutos y } \\
32 \text { minutos respectivamente. Sirvió a los militares para ejercitar el concepto } \\
\text { de pool. }\end{array}$ \\
\hline Mayo 1987 & $\begin{array}{l}12 \text { miembros viajan a Camp Lejeune (Carolina del Norte) para cubrir la } \\
\text { "Operación Solid Shield 87". Fue el primer pool en el que se mandaron } \\
\text { las crónicas como mensajes clasificados al Pentágono para que se pudiera } \\
\text { transmitir en el momento del ataque. Problemas en los helicópteros retrasó } \\
\text { el transporte de los corresponsales en la zona de asalto, esto hizo que se } \\
\text { planificara un plan alternativo para las futuras operaciones. }\end{array}$ \\
\hline Julio 1987 & $\begin{array}{l}10 \text { corresponsales viajan para cubrir la "Operación Earnest Will", durante } 9 \\
\text { días, la primera en la que la Marina estadounidense escolta varios petroleros } \\
\text { kuwaitíes por el Golfo Pérsico. Se mantuvo en secreto durante tres días. }\end{array}$ \\
\hline Marzo 1988 & $\begin{array}{l}\text { Primera operación en la que el aviso se realiza con poco tiempo. Los militares } \\
\text { contaron con seis horas para desplegar a los } 10 \text { corresponsales que durante } \\
\text { dos días cubrirían el despliegue de emergencia de las tropas estadounidenses } \\
\text { en Honduras ante la invasión de Nicaragua ("Operación Golden Pheasant } \\
88 \text { "). No se incluyeron en un primer momento a los fotógrafos de revistas, } \\
\text { pero luego se accedió que se incorporaran ya en Honduras. }\end{array}$ \\
\hline $\begin{array}{c}\text { Diciembre } \\
1988\end{array}$ & $\begin{array}{l}11 \text { corresponsales cubren durante cuatro días por primera vez una operación } \\
\text { en un ambiente frío. Reciben entrenamiento y tras la operación cuando } \\
\text { analizan con los medios la experiencia, los escritos reclaman mayor tiempo } \\
\text { para entrevistar a los soldados, algo que se estudiará en el futuro. }\end{array}$ \\
\hline Mayo 1989 & $\begin{array}{l}12 \text { miembros del pool acompañan al primer avión que traslada al Cuerpo de } \\
\text { Marines para aumentar las fuerzas en Panamá el } 12 \text { de mayo como parte de } \\
\text { la "Operación Nimrod Dancer". Las crónicas se envían directamente a los } \\
\text { medios, no como en las anteriores operaciones que pasaban por el Pentágono. }\end{array}$ \\
\hline
\end{tabular}

Pero la prueba de fuego se produciría en 1989 con la invasión de Panamá (Contreras \& Sierra, 2004).

\section{Invasión de Panamá (1989)}

El 20 de diciembre, 24.000 tropas americanas tomaron parte de la operación más grande después de Vietnam, la invasión de Panamá, que supuestamente tenía como objetivo arrestar al líder panameño, el General Noriega, por un cargo de tráfico de drogas (Knightley, 2000). La llamada "Operación Causa Justa", se caracterizó por 
una mala planificación, y la desinformación hizo que la prensa volara tarde y se perdieran el inicio de la invasión (Mijallo, 2004).

El Secretario de Defensa, Dick Cheney, debatió con el presidente George W. Bush y el vicepresidente Dan Quayle, la participación de la prensa durante la organización de la invasión. La semana anterior a la invasión ambos mostraron a Cheney sus dudas sobre que los medios pudieran mantener la seguridad de la operación y le dejaron la última decisión sobre cómo manejar a la prensa. Cheney decidió solo unas horas antes de que la operación comenzara utilizar el modelo del pool pero debido a la tardía notificación, en la planificación militar no se incluía la posibilidad de incorporar reporteros en las unidades de acción, por lo que todo se retrasó (English, 2005). Según la periodista, Jacqueline Sharkey (1991), todo fue intencionado y las restricciones que sufrió la prensa se debieron a motivos políticos.

Los periodistas del pool fueron citados dos horas antes del comienzo de la invasión, pero esta anticipación no sirvió de nada, porque embarcaron siete horas después y una vez en Panamá, debieron permanecer otras cuatro horas en una base militar norteamericana (Shor, 1998). Durante los dos primeros días, sólo pudieron informar desde la base aérea de Howard. El resto de los cien periodistas que habían acompañado a las tropas con la promesa de que alguno de ellos podría ser incluidos en el grupo, se vieron obligados a volver a casa, ya que no se les llegó a dar acceso (Knightley, 2000). Oficialmente, la selección de los participantes en un pool era aleatoria pero en esta invasión, según Pizarroso et al. (2007), fueron las consideraciones propagandísticas, empresariales y hasta de amistad las que finalmente influyen a la hora de decidir.

El general Maxwell R. Thurman, que dirigió las operaciones militares, criticó el trato que recibió por parte de la prensa, justificando que no podía destinar cinco o seis helicópteros para desplazar sólo a los corresponsales. También afirmó que las televisiones requerían volver de las operaciones a las cuatro para poder entrar en el informativo de las seis e incluso reveló que éstas retrasaron la salida de Noriega de la nunciatura, porque no estaban conectadas con el satélite. A su parecer el sistema pool funcionó mal porque "era una mezcla de quién era más importante y a quién le correspondía. En la mayoría de los casos ganaban los más importantes. Si tuviera que hacerlo de nuevo, le daría la mayor prioridad al cuerpo de prensa regular del Pentágono" (Shor, 1998:73-74). Varios reporteros que no formaban parte del pool salieron por su cuenta y tuvieron mucho más éxito a la hora de cubrir los eventos (Kim \& Paul, 2004).

Las decisiones de ignorar las recomendaciones de la comisión Sidle, excluyendo a los medios mientras que la operación se llevaba a cabo y luego controlando fuertemente y censurando la información fueron decisiones que se hicieron desde el nivel más alto del gobierno (Belknap, 2002). Las tropas norteamericanas, además, durante la invasión dificultaron en todo momento el trabajo de la prensa, incluso llegaron a asesinar al fotógrafo del diario El País, Juan Rodríguez y allanaron las oficinas de la agencia centroamericana de Noticias, Acan-EFE (Beluche, 2004). 
Lo ocurrido en la invasión de Panamá fue uno de los mayores ejemplos de control de los corresponsales de prensa en zonas de conflictos. Los medios fueron secuestrados, recibiendo sólo la información que los militares daban en las ruedas de prensa (Bruner, 1997). Al final tanto militares como los medios consideraron un fracaso la cobertura de Panamá, la prensa por los límites de acceso y la pobre logística, y los militares por la falta de planificación (English, 2005).

En respuesta a las críticas de los medios de información, el Ayudante del Secretario de Defensa para los Asuntos Públicos, Pete Williams, pidió al periodista de la agencia Associated Press, Fred S. Hoffman, examinar la cobertura de la "Operación Causa Justa”, para determinar qué se había hecho mal (English, 2005).

Hoffman, presentó su informe en diciembre de 1989, en él, evidenció que el personal de los Asuntos Públicos, no había participado en la planificación de la operación y que el mal funcionamiento del fax, la falta de personal en el Pentágono, más los problemas de comunicación desde el centro de prensa en la base de Quarry Heights en Panamá, provocó serios retrasos en las crónicas y fotografías del pool. Justificó la frustración de los corresponsales afirmando que se les llevaba a zonas que nada tenían que ver con los combates y que además tuvieron que soportar acusaciones de estar siendo manipulados por la administración Bush (Hoffman, 1989).

En el informe también sugería 17 recomendaciones para mejorar el procedimiento. Entre ellas, que el pool se dividiera en dos secciones, la primera, muy pequeña, estaría formada sólo por reporteros y fotógrafos y la segunda, que se incorporaría más tarde, incluiría los equipos de apoyo, como el de retransmisión vía satélite. También solicitaron que los militares de apoyo del pool tenían que pertenecer a la rama de las Fuerzas Armadas que realizara la operación, ya que en Panamá los tres oficiales pertenecían a la Marina y a la Fuerza Aérea cuando la operación estaba siendo llevada a cabo por el Ejército (Hoffman, 1989).

Tras el informe, los militares se vieron obligados a revisar los procedimientos con la prensa. El Jefe del Estado Mayor, el general Colin Powell mandó una directiva a los principales comandantes militares norteamericanos en mayo de 1990, solicitando una mayor participación de los medios en la planificación de futuros conflictos militares. Remarcaba: "Se recuerda a los comandantes que los medios en las operaciones militares son importantes (...) y merecen su atención personal planificar el National Media Pool del Departamento de Defensa (DoDNMP), es un requisito para todos los planes de contingencia". Informaba que además se elaboraría una nueva directiva tras evaluar y resolver los problemas del pool surgidos en la "Operación Causa Justa", pero recordaba las pautas a seguir con los medios como el dar diariamente una rueda de prensa con material desclasificado de forma comprensiva, que no se excluyera a la prensa justificando razones de seguridad o proponía que se dividieran los grupos de prensa entre 1-3 personas, siendo acompañados los 16 corresponsales por 3 oficiales, además de suministrarles equipación apropiada (cascos, chalecos antibalas, cantimploras, etc.), acceso a las comunicaciones y asistencia sanitaria (Powell, 1990). 
Esta directiva ayudó a cambiar actitudes sobre los medios y concienciar a los líderes veteranos que la planificación de los Asuntos Públicos era una parte importante de la planificación de la operación (Venable, 2002).

\section{Operación Escudo del Desierto y guerra del Golfo (1990-1991)}

El 30 de marzo de 1990, se estableció una nueva guía que pondría en marcha, cinco meses más tarde, con la invasión de Kuwait, el 2 de agosto de 1990, por parte Saddam Hussein. Pero nuevamente falló y reabrió los debates sobre el acceso de los medios en las operaciones militares. Tras la invasión se activó el pool para cubrir los primeros estados de la "Operación Escudo del Desierto". Durante las tres primeras semanas, el pool satisfizo tanto a militares como a periodistas, los medios tuvieron acceso a situaciones que no podrían cubrir de otra manera y los militares eran capaces de asegurar una cobertura positiva. Pero esto cambió cuando se pasó de una postura defensiva a una ofensiva, ya que las limitaciones de acceso supusieron quejas de la prensa (Combelles-Siegel, 1996).

En enero de 1991, Estados Unidos lideró las fuerzas de la coalición en la llamada, "Operación Tormenta del Desierto", expulsando a los iraquíes que habían invadido Kuwait (Morera Hernández, 2012).

Militares estadounidenses y británicos trabajaron juntos permitiendo sólo el acceso al campo de batalla a un número limitado de periodistas. Estos estarían escoltados por oficiales que decidirían qué se podía ver y los artículos estarían a su libre disposición. Los grupos mediáticos se quejaron de la censura que sufrían pero aceptaron las condiciones porque no tenían otra elección. Así que el Pentágono estableció que la cobertura de la guerra se realizaría en régimen de pool. Un número limitado de corresponsales visitarían, escoltados por oficiales militares, algunos de los puntos elegidos por los ellos y luego mandarían sus informaciones a Arabia Saudí donde se compartirían con el resto de compañeros (Knightley, 2000).

Cada reportero de pool y medio de comunicación tenían que firmar un acuerdo formal en el que establecía qué podían esperar los periodistas de los militares. Sería el origen del programa que después se desarrollaría en la guerra de Irak de 2003, los llamados "empotrados" o "embedded", corresponsales que convivían con las tropas en el frente. Entre otras cosas se les ofrecía una cama, casco y chalecos antibalas, comida, transporte y el mismo nivel de protección que el resto de los soldados. A cambio los militares se reservaban el derecho de revisar el material como medida de seguridad (Cole, 2014).

Las primeras tropas abandonaron Estados Unidos rumbo a Arabia Saudí el 7 de agosto, pero ningún corresponsal les acompañaba. El Pentágono todavía no había activado el prometido pool y los periodistas que solicitaban el visado para viajar al país, se les era denegado. El Pentágono justificaba el empleo del pool por la peligrosidad del escenario y la necesidad de no poner en riesgo a los corresponsales, entendía 
que el acceso al frente tenía que ser muy limitado. Días más tarde, el Departamento de Defensa consiguió los visados para los 17 periodistas que formarían parte del pool, 7 corresponsales de televisiones, 5 de agencias de noticias, 2 de periódicos, 2 de magazines y 1 de radio (Suárez, 2013).

Estos llegaron a Arabia Saudí el 13 de agosto y desde entonces eran controlados en todo momento por oficiales del Pentágono que les dejaron claro que si hacían preguntas complicadas, se les consideraría "anti militares" y serían tratados de tal forma. En esos momentos sólo había una historia que contar y era que no había suficientes tropas americanas en la zona para emprender un ataque a Irak, pero el Pentágono amenazó a los reporteros asegurándoles que si querían seguir en Arabia Saudí no podían revelar esa información. Estos aceptaron la prohibición y no informaron de ello. Algunos periodistas y pequeños medios de comunicación, excluidos del pool, decidieron denunciar al Pentágono alegando que ese sistema violaba el derecho a la libertad de expresión. Según Knightley (2000), ningún grupo de comunicación grande quiso apoyar la protesta, en parte por miedo a ser expulsados del pool o sentar un peligroso precedente si perdían judicialmente. Al final la guerra terminó antes de que los jueces se pudieran pronunciar, así que nuevamente los militares ganaron la batalla dividiendo a los medios de comunicación.

En Gran Bretaña, el Ministerio de Defensa, anunció también que la cobertura del conflicto se haría en régimen de pool obligando a los corresponsales a aceptar todas sus normas. Prensa escrita o audiovisual, tenía que pasar por el censor antes de mandar su material a Londres y además tendrían que llevar uniforme militar durante todo el tiempo que durara la contienda (Knightley, 2000).

A lo largo del conflicto, de los 1.600 periodistas que estaban en Arabia Saudí, sólo 186 fueron acreditados para estar en el pool escoltados con unidades de combate. Estos firmaron un compromiso escrito con diecinueve normas, entre las que estaban: "no informar sobre las operaciones en curso o futuras o sobre los lugares concretos donde se producen los hechos hasta que sea autorizado expresamente; no hablar de la efectividad del enemigo ni de las bajas propias hasta que concluyan las operaciones de rescate o se informe a los familiares; el éxito o fracaso de una operación será descrito en "términos genéricos", y el jefe de la unidad podrá vetar o embargar las informaciones". No permitían las conexiones en directo y a pesar de tener acceso al campo de batalla, dependían de un sistema de comunicaciones poco fiable para poder enviar sus crónicas, además los teléfonos móviles, grandes y pesados, de la época estaban prohibidos. Toda la información estaba bajo el control del Pentágono y era revisada antes de ser enviada a los EE.UU. a través de medios de transmisión militares. Estos en muchas ocasiones retrasaban su emisión, algo que era criticado por los corresponsales (Prados \& Altares, 2003).

Los periodistas que no formaron parte del pool, sólo tenían la opción de cubrir la guerra desde sus hoteles en Arabia Saudí a través de la rueda de prensa diaria que daban los aliados, sin responder a las preguntas de los periodistas. Los corresponsables o aceptaban esto o se volvían a casa (Knightley, 2000). Los gobiernos y limitares 
temían que la presión mediática sobre la población pusiera en peligro la intervención militar, por eso se evitó mostrar los efectos reales de la guerra, siendo las televisiones cómplices (Braojos Garrido, García González, De Pablo Contreras, Paz Rebollo \& Scuzle Schneider, 1999).

Otra forma que tenían los militares de controlar la información fue restringiendo las comunicaciones, los corresponsales se encontraban en un área militar y los medios que tenía a su servicio eran extremadamente lentos y por ello, cuando algo llegaba a las redacciones tres días después resultaba totalmente inútil y no se publicaba (Suárez, 2013).

Varios periodistas frustrados se encargaron de eludir los controles militares y aventurarse unilateralmente en la primera línea arriesgando sus vidas (Kim \& Paul, 2004).

El reino de la imagen fue absolutamente monopolizado por la televisión, incluso alguno de sus fotogramas suplantaron a las fotografías en la prensa. Y eso que fueron escasas las imágenes por televisión. Esta escasez fue consecuencia de la exclusión de muchos fotógrafos de los pool, táctica de control de la información. Sólo se acreditó a 33 fotógrafos y los centros de revelado que se les construyó se encontraban a unas tres horas de la zona de combate, por lo que los militares tenía un mayor control, evitando el envío de imágenes de solados aliados muertos o heridos o de víctimas iraquíes (Suárez, 2013).

\section{Conclusiones}

La relación entre los militares y los corresponsales ha ido evolucionando en cada conflicto. Tras las amargas experiencias de sus inicios, los militares han intentado controlar la información mientras que los corresponsales, han buscado lo contrario, tener mayor libertad para comprobar in situ lo que estaba sucediendo. Esta pugna constante, encontró un punto de encuentro en la Comisión Sidle, que sentaría las bases del National Media Pool del Departamento de Defensa (DoDNMP) estadounidense o pool informativo.

Lo que daría paso a un nuevo sistema informativo, ya que establecería unas normas básicas para que por lo menos algunos corresponsales pudieran cubrir los primeros estados de un conflicto. Para ello, se les integraría en la planificación militar y viajarían y convivirían con las tropas en el frente, siendo el origen de los modernos corresponsales de conflictos, los llamados "empotrados". Los reporteros seleccionados que eran citados horas antes del inicio de las operaciones, luego tenían que compartir su material con el resto de medios.

Esta medida no solucionó los problemas porque muchas veces los militares los citaban con retraso, otras veces no les llevaban dónde se estaba produciendo la acción y en otras ocasiones, los militares controlaban la información, restringiendo las comunicaciones. 
Pero es evidente que el pool informativo marcó un punto de no retorno, ya que esta medida que parecía acercar posturas, lo que sentó fueron las bases para controlar más a los medios. Sólo un número limitado de corresponsales podrían cubrir los primeros estados de una operación, aceptando, además, cualquier norma impuesta por los militares. Obligando, por tanto, al resto de los corresponsales fuera del circuito, a arriesgar sus vidas, para poder informar con objetividad.

\section{Referencias bibliográficas}

BELKNAP, M. H. (2002). The CNN Effect: Strategic Enabler or Operational Rish? Parameters, $n^{\circ} 32$ (2). p.100-114.

BELUCHE, O. (2004). La verdad sobre la invasión. Panamá: Manfer.

BRUNER, G. P. (1997). Military-Media Relations in Recent U.S. Operations. Air University.

CECIL, K., \& SULLIVAN, M. (1989). Media war coverage and Pentagon policy. Cambridge: Harvard University.

COLE, R. (2014). Holding the line. Index on Censorship, $n^{\circ} 43(1)$. p. 78-81.

COMBELLES-SIEGEL, P. (1996). The troubled path to the Pentagon's rules on media access to the battlefield: Grenada to today. Carlisle: U.S Army War College.

COMISIÓN SIDLE. (1984). Final report of the CJCS Media-Military Relations Panel . Washington: Office of Assistant Secretary of Defense.

CONTRERAS, F. R., \& SIERRA, F. (2004). Culturas de guerra : medios de información y violencia simbólica. Madrid: Cátedra.

ENGLISH, E. L. (2005). Towards a More Productive Military-Media Relationship. Fort Leavenworth: U.S. Army Command and General Staff College.

HOFFMAN, F. S. (1989). Review of Panama pool deployment.

KIM, J. J., \& PAUL, C. (2004). Reporters on the Battlefield: The Embedded Press System in Historical Context. Rand Corporation.

KNIGHTLEY, P. (2000). The First Casualty. The war correspondent as hero and myth-maker from the Crimea to Kosovo.London: Prion Books.

MIJALLO, Ó. (2004). Viejos y nuevos "empotrados", testigos de excepción. Cuadernos de periodistas, $\mathrm{n}^{\circ}$ 0, Madrid: APM. p. 57-65.

MORERA HERNÁNDEZ, C. (2012). "La invasión norteamericana de Granada: imágenes y discursos en la prensa española (1983)". Actas del Congreso Internacional "América Latina: La autonomía de una región” (2012). Madrid: Trama editorial. p. 547-557.

MORERA HERNÁNDEZ, C. (2012). Operación Tormenta del Desierto: guerra y encuadres noticiosos en la prensa española (1991). Razón y palabra, $\mathrm{n}^{\circ} 79$.

PIZARROSO QUINTERO, A.; GONZÁLEZ SAN RUPERTO, M.; SAPAG MUÑOZ DE LA PEÑA, P. (2007). Periodismo de guerra. Madrid: Síntesis.

POWELL, C. (1990). DOD National Media Pool Planning Requirements. Washington: Joint Chiefs of Staff.

SHARKEY, J. E. (1991). Under fire. Washington: The Center for Public Integrity. 
SHOR, R. (1998). Historia y poder de la prensa. Barcelona: Andrés Bello. TERRY, C. J. (1997). Press access to combatant operations in the postpeacekeeping era. Military Law Review, $\mathrm{n}^{\circ} 154$. p. 1-26.

VENABLE, M. B. (2002). The Army and the Media. Military Review.p.66-71.

6.1 Referencias web

PRADOS, L., \& ALTARES, G. (2003). La guerra mejor contada de la historia. 6 de abril de 2003. Consulta 13 de octubre de 2014. En: http://elpais.com/ diario/2003/04/06/domingo/1049601153 850215.html

SUÁREZ, R. (2013). El tratamiento informativo de los conflictos bélicos. Consulta 28 de octubre de 2014. En: http://www.comunicacionymedios.com/comunicacion/television/textos/roberto_suarez_tratamiento_conflictos.htm

THE NEW YORK TIMES. (1984). Text of journalists' joint statement. 11 de enero de 1984. Consulta 20 de octubre de 2014. En: http://www.nytimes.com/1984/01/11/ world/text-of-journalists-joint-statement.html?pagewanted=print 